Boise State University

ScholarWorks

4-1-2010

\title{
Who Moved My Intranet? The Human Side of Introducing Collaborative Technologies to Library Staff
}

Keven Jeffery

San Diego State University

Ellie Dworak

Boise State University 


\title{
Who Moved My Intranet? The Human Side of Introducing Collaborative Technologies to Library Staff
}

\author{
Keven Jeffery \\ San Diego State University \\ Ellie Dworak \\ Boise State University \\ Introduction
}

In the Fall of 2007, the San Diego State University (SDSU) Library changed from an HTML intranet to a Wiki intranet (Dworak \& Jeffery, 2009) using the MediaWiki software. This change was carried out by a group of three people (two librarians and an IT staff person who was the intranet webmaster). In doing so, the group shifted the responsibility for content development and maintenance from a single webmaster (with several backups) to all library employees. This change was made in the hopes that this would lead to a more dynamic, relevant, and current intranet. In order for such a major reallocation of accountability to be successful, library employees had to be persuaded to participate in this process. Without voluntarily participation, the move to this new, more dynamic format would be a wasted effort. This paper explores the measures that were taken to try to garner involvement in this technology change, analyzes the results of these efforts, and offers suggestions and next steps.

\section{Literature Review}

Intranets, according to Mphidi and Synman, 2009, can, among other things, be used to share knowledge, create trust, and improve decision making and services (p. 394). They are therefore an important addition to the communication tools of any large organization, including libraries. The development of a successful intranet has been compared to an evolutionary process that occurs over time and involves a range of actors within an organization (Martini, Corso \& Pellegrini, 2009 p. 295-296). It is consequently important in the success of an intranet to create value for both the organization, and the employees who will rely on it as a communication tool. A key part of this process is to involve everyone in the project (p. 301).

Evaluations of library intranets, however, have found that librarians and professionals can be more invested in online communication than are supporting staff members, who can be unaware of the tool, or believe it not targeted to them (Robbins, Engel \& Bierman, 2005, p. 270). While it is no doubt important to have top-level encouragement for Web 2.0 adoption (Köhler-Krüner, 2009, p. 42-43), it is perhaps more important that staff members are completely involved. S taff should be fully invested, not only as an exercise in morale building, but also because many students have been found to not differentiate between the types of library employees assisting them. These students expect all library employees to have the tools to answer their questions in a satisfactory manner (Sult \& Evangeliste, 2009, p. 249-250). If staff members are left out of the information sharing process, it could be argued that library patrons are in danger of not receiving as high a level of service as they should.

Creating this online collaboration and information sharing between organizational actors is strength of Wiki software. Wikis can be used as storehouses of institutional knowledge, aiding reference desk staff (Dworak \& Jeffery, 2009, p. 404) and can perhaps more importantly become a "collective resource" helping to remind each employee that they are responsible for intranet content (p. 409). Wikis, like any Web 2.0 tool, are also useful as they democratize access to the method of creating content, avoiding the danger that information technology staff are the only drivers of software adoption (Köhler-Krüner, 2009, p. 42).

Intranets can be unsuccessful for a multitude of reasons, including the failure to consider the organization goals, lack of vision, absence of commitment, responsibility conflicts and role misunderstandings (Martini, Corso \& Pellegrini, 2009 p. 296). It seems that the collaborative nature of the Wiki can overcome many of these issues, especially in an organization where there is a continuous drive for improvement (Köhler-Krüner, 2009, p. 42). 


\section{Gaining Involvement}

The SDSU Library is a fairly large organization, with 28 library faculty, 53 staff members and 4 administrators. The library has few (one or two) layers of management between front-line employees and the Dean of the Library. While technology change always requires a level of staff buy-in, it is crucial in an organization where individuals are given a great deal of responsibility for determining how they do their daily work, as is the case in a flatly structured organization.

The methods that this group used to build staff involvement require effort in the areas of communication and training. Anecdotally, the major reasons for technology adoption failures at the SDSU library are that a) the person didn't know who to talk to or that the service was available, b) the person is intimidated by the change and c) the person felt too busy to dedicate time to learning something new. By offering training and support, we tried to alleviate the concerns about the Wiki being too complicated or otherwise intimidating, offer employees a dedicated time to learn the new tool, and continuously market the new software.

Recognizing the importance of buy-in, the intranet team encouraged involvement by doing the following:

\section{- Conducting pre- and post-surveys}

The main point of the pre-survey was to gain an understanding of how the current HTML-based intranet was being used and what could be improved. The focus of the post-survey was to determine the success of the Wiki transfer and to discover any needs for follow-up. However, both had the hidden benefit of reminding people that an intranet is not a static apparatus that is imposed upon them by the IT department, but a shared tool meant to be used and useful. It also indicated to library employees that the team cared about their opinions and were considering them while developing a project plan. This is vital because without trust the chances of gaining acceptance for a major change are slim.

- Transferring the old Intranet content from HTML to Wiki markup language.

Once the pre-survey was complete and a Wiki was chosen as the best solution, the content transfer was done almost exclusively by the project group. While such an action may appear to decrease involvement, presenting a ready to use product made the transition easier and encouraged future involvement by removing a large, time intensive block of work. Library personnel understandably react more positively to being told that they are being facilitated to do creative work than they do to being asked to add something new to their workload.

\section{- Conducting several hands-on Wiki editing workshops}

Arguably the most important action in increasing comfort with the new internet was a series of Wiki-editing workshops held by the project group. These workshops were scheduled strategically so that staff had a choice of the most convenient time. During training, each attendee was issued a login and password, which they could then use to edit the Wiki. Handouts were given outlining the basics of Wiki markup and library web procedures. After a brief introduction, the majority of the hour session was spent adding and editing content in the Wiki. This allowed some staff to get comfortable enough to accept the project right away, while others felt the need for more help. Individuals were encouraged to come to multiple workshops if they wanted to, and one-on-one help was offered to those who felt the need.

- Recruiting several Wiki administrators to serve as departmental experts

After each workshop, attendees were asked if they would like to be given administrative rights to the Wiki, which would allow them to create and erase pages, and to assign user names and passwords (Wiki users who do not have administrative privileges can only edit existing pages). Our goal was to have one Wiki administrator per Library department. We found that we easily met this goal, and that many departments had more than one administrator. This created a support system for those who forgot information, needed help, or were new to the library. It also initiated a group of advocates who were excited about the project. 


\section{- Email and in-person communications}

Throughout this process, many emails were sent updating Library staff on the progress of the project, next steps, and workshop opportunities. Through written email communication and verbally during workshops, we encouraged questions and comments and offered to help with any problems that came up. Quite a few people took us up on these suggestions and either offered their feedback, asked for help, or both. In fact, we recruited other Wiki administrators via these communications.

Our ability to build involvement was enhanced by several factors. First, one section of the intranet is a heavily used and often updated Ready Reference File. This knowledge base is comprised of the shared institutional experience of the reference staff and includes such information as "how to find resources for that difficult English 476 assignment" and "how to locate theses and dissertations in the online catalog." As with the rest of the intranet, prior to implementation of the Wiki, changes to the Ready Reference File had to be made by sending requests to one of the several people with access and the ability to make changes to the HTML documents. Unlike some portions of the intranet, the Ready Reference File requires continuous updating as assignments, item locations, and other necessary information changes frequently. Further, of out-of-date content was noticed immediately because of the public service nature of the subject matter. Employees who worked at the reference desk saw immediate value in being able to update the Ready Reference File on their own and the project gained traction fairly quickly within this department.

Also to our advantage was the fact that during this time period the library was undergoing a round of strategic planning, for which frequent status updates and draft reports from several strategic planning groups were being distributed amongst library staff. The Wiki was an excellent place to post such documents. Unlike with email, people were not being inundated with draft after draft of planning group reports, but instead could find the latest version on the Wiki at their convenience. The MediaWiki software used for the project includes automatic version tracking so that people could see what had changed, or the group could revert to an earlier version in the event of an error.

Finally, several library employees felt that the Wiki had great potential value and championed the project from the start, both posting materials and encouraging others to do so. While one of these people was an administrator, it was more a matter of cultural adjustment than a top-down impetus that caused the change to take hold. Because several people were posting materials to the Wiki and directing others to read them there, it became an obvious option for the distribution of materials.

Despite the significant efforts put into training and communication, we found room for improvement. Rather than only give user-level passwords to people who attended a workshop, everybody in the Library should have been issued a password. This would have allowed people to practice and try out the Wiki software prior to making a decision about attending a workshop, and may have encouraged them to come. Still others may not have needed to attend a workshop, given that the software is fairly intuitive. It also would have been a good idea to hold workshops after the project roll-out, rather than consider them exclusively a pre-launch portion of the project.

\section{Survey Results}

The project team has conducted three surveys during the course of this project. The first two, mentioned earlier, were carried out directly before and after the implementation. The first, a pre-survey, was used to gauge the need for the change as well as to determine direction, while the second, a post-survey, was used to assess our success. More discussion of these surveys can be found in Dworak and Jeffery, 2009.

A follow-up survey was sent approximately one year after the post-survey and approximately two years after the Wiki implementation, to help measure our success in integrating the shift from centralized to a distributed intranet management, as well as to determine the need for more efforts in this regard. It is this survey that we will discuss in depth in this paper. This survey was changed considerably from the first two surveys, as we were looking for information regarding training needs and integration issues, rather than trying to ascertain a need for a new software 
product or to determine its technical success. As a side note, these surveys were not conducted as statistical studies, but as tools to help us guide and direct the project.

The recent follow-up survey found that of the 40 employees responding to the survey, $98 \%$ had used the Wiki to look up information at least once over the past 6 months, and $78 \%$ had reported using it at least once a week. In comparison, $53 \%$ of our staff used the intranet at least once a week prior to the Wiki implementation and $64 \%$ used it directly post-implementation (Dworak \& Jeffery, 2009, p. 407). This upward trend suggests that the Wiki has become an increasingly valuable information source for the library faculty and staff.

As might be imagined, there were far fewer Wiki editors than there were Wiki readers, only half of the follow-up survey respondents $(48 \%)$ reported making a change to the Wiki themselves. The types of information users reported updating most often were the reference department Ready Reference File (28\%), committee information (23\%), department information (23\%) and information related to a recent library strategic planning initiative (26\%). This shows a noticeable increase in changes initiated by staff over our previous surveys. Before the Wiki project, only $28 \%$ of survey respondents instigated a change to the intranet by any means, including asking the Webmaster to make a change. In the second, post-Wiki survey, this number jumped to $40 \%$ (Dworak \& Jeffery, 2009, p. 407).

The $50 \%$ of respondents who did not report making a change to the Wiki themselves also did not contact Wiki administrators to make changes for them. These individuals did, however, report using the Wiki content, as $95 \%$ had visited the Wiki over the past 6 months and $65 \%$ visited it at least once a week. $70 \%$ of the individuals who chose not to update content were staff members, not librarians, and only $30 \%$ of these non-editors had received any training in using the Wiki software. It was interesting to note, however, that $45 \%$ of these non-editors were interested in receiving more Wiki training, suggesting that there is an opportunity to involve some of them in the content management process.

Acceptance of the Wiki as a communication tool seems to be largely spearheaded by librarians. $83 \%$ of the 17 librarian respondents reported using the Wiki at least once a week and $65 \%$ reported changing Wiki content themselves. This can be compared to the 22 library staff respondents, of whom a slightly smaller number, $73 \%$, reported visiting the Wiki at least once a week, but only $32 \%$ had made a ch ange to the Wiki themselves. Furthermore, while $50 \%$ of librarians reported that they were more likely to update content because of the Wiki, only $27 \%$ of support staff reported a similar feeling.

At the SDSU library, the responsibility for updating online content is largely shared by librarians and staff. The different rates of acceptance by librarians and support staff might be explained by the greater success in marketing training sessions to librarians during the launch of the Wiki. $60 \%$ of librarian respondents reported having received Wiki training either in a workshop or individually, while only $41 \%$ of staff reported the same. There was also a significant difference between librarians and staff members regarding the perception of the Wiki being easy to use on their own. $41 \%$ of the librarian respondents stated the Wiki was easy to use without help, while only $14 \%$ of staff had a s imilar feeling. Our survey did not investigate why this might be, but librarians do have expertise in navigating interfaces and may not find the Wiki software to be more difficult than some of our more complex research databases.

The difference between librarian and staff adoption might also be explained by the fact that librarians have a more immediate need to share information, as with the Ready Reference File. However, the latest survey suggests that the library could do a better job of marketing the Wiki and providing Wiki training to library support staff. Perhaps part of this process could involve encouraging the posting of materials that would be of more interest to staff members, such as department manuals and training material, in the Wiki format.

\section{Overview of Recommendations}

New technology implementations fail for many reasons, the most critical being a situation where there is no significant need. When trying to develop projects that benefit from distributed input, it is important that project initiators not get caught up in the trendiness of a technology, or the fact that they themselves would like to use it, 
and forget to analyze the real benefits and goals of their mission. This is easy to do, because often the people implementing such a project are engaged in, and enjoy using new technologies.

Once a real need has been determined, it is important to time a project so that it is not competing with other big technology projects. However, there are always other things going on in a library, so perfect timing may not be achievable. Instead of looking for the ideal time, determine how the change or new tool can support any ongoing or short-term work. Our example, above, is that the strategic planning process benefitted from the Wiki, which helped facilitate the adoption and acceptance process. If such convergences are identified, forge contacts with the leaders of those efforts and see if they are willing to become champions.

Just as important as a real need is a perceived need. The new technology may indeed improve processes or outcomes, but if people don't realize this, they will not feel a need to engage. For this purpose, words are not as effective as experience. Thus, hands on workshops and follow up are important. Providing real time for people to try a new product is crucial, as is following up with refreshers and opportunities for new people (who may not be first adopters, but have heard how great the new tool is). The hands-on nature of these sessions cannot be stressed enough, since it's by actually using the new technology that they may begin to understand its utility. Ideally workshops will be followed with real use, such as in our case where employees posted strategic planning documents and made changes to the Ready Reference File. This will reinforce the learning that takes place in a classroom and encourages the new direction.

While technical skills are highly valued in libraries, the person doing the back-end work does not always have time to manage the training and ongoing communication needed for a successful project. It's important to pull together an implementation team that includes somebody who can serve as a main point of contact for questions and concerns, can arrange and market training sessions, and who will identify the need for further training as the project continues. Too many projects become orphaned after an initial push because this final step is ignored.

Finally, throughout a new technology roll-out, attention should be given to your champions. These people may work at any level of the library, from management to student employees, or anywhere in between. They are the ones whose eyes light up when you offer a workshop, who ask questions, and who seek opportunities to use the tool. Look for opportunities to send these people out as disciples and assistants - often, they are happy to be asked.

\section{Conclusion}

There are many factors in the success of integrating and accepting a new technology in a library. The two most important are a real and perceived need. Also crucial are plentiful training opportunities. Secondary to that are favorable circumstances and the nurturance of early adopters. If attention is given to all of these areas, a technology project is much more likely to succeed. 


\section{Appendix}

\section{About the respondents:}

\begin{tabular}{|l|l|l|l|l|}
\hline Respondents & Number Responding & \% of Respondents & Total in Library & $\begin{array}{l}\text { \% of Total in } \\
\text { Library }\end{array}$ \\
\hline Librarians & 17 & $42.5 \%$ & 28 & $33 \%$ \\
\hline Staff & 22 & $55 \%$ & 53 & $62 \%$ \\
\hline Administrators & 1 & $2.5 \%$ & 4 & $5 \%$ \\
\hline Total & 40 & $100 \%$ & 85 & $100 \%$ \\
\hline
\end{tabular}

\section{Responses by employee type:}

\begin{tabular}{|l|l|l|l|}
\hline Question & $\begin{array}{l}\text { Librarian } \\
\text { Respondents (17) }\end{array}$ & $\begin{array}{l}\text { Staff } \\
\text { Respondents } \\
\mathbf{( 2 2})\end{array}$ & $\begin{array}{l}\text { All } \\
\text { Respondents } \\
\mathbf{4 0}\end{array}$ \\
\hline Used Wiki over the past 6 months & $100 \%$ & $95 \%$ & $98 \%$ \\
\hline Used Wiki at least once a week & $83 \%$ & $72 \%$ & $78 \%$ \\
\hline Initiated a change through an administrator & $11 \%$ & $18 \%$ & $18 \%$ \\
\hline Initiated a change themselves & $65 \%$ & $32 \%$ & $48 \%$ \\
\hline Changed the Ready Reference File & $47 \%$ & $10 \%$ & $28 \%$ \\
\hline Changed committee information & $29 \%$ & $14 \%$ & $23 \%$ \\
\hline Changed strategic planning information & $29 \%$ & $19 \%$ & $26 \%$ \\
\hline Changed department information & $18 \%$ & $29 \%$ & $23 \%$ \\
\hline Changed procedural information/manuals & $12 \%$ & $14 \%$ & $13 \%$ \\
\hline Received training & $60 \%$ & $41 \%$ & $51 \%$ \\
\hline Learned on their own & $35 \%$ & $43 \%$ & $39 \%$ \\
\hline Would like more training & $29 \%$ & $45 \%$ & $42 \%$ \\
\hline Think the Wiki is easy to use & $41 \%$ & $14 \%$ & $26 \%$ \\
\hline More likely to make a change because of Wiki & $50 \%$ & $40 \%$ \\
\hline
\end{tabular}


About the 20 respondents $(50 \%)$ who had never initiated a change to the Wiki:

- They also did not make a change through the administrator (95\%)

- $\quad$ They used the Wiki regularly

o $95 \%$ over past 6 months

o $65 \%$ at least once a week

- $70 \%$ were staff members

- $30 \%$ were librarians

- Only 30\% had received any training

- $45 \%$ wanted more training 


\section{Bibliography}

Dworak, E., \& Jeffery, K. (2009). Wiki to the rescue: Creating a more dynamic intranet. Library Hi Tech, 27(3), 403-410.

Köhler-Krüner, H. (2009). Best practices for implementing enterprise 2.0. Infonomics, 23(4), 40-45.

Martini, A., Corso, M., \& Pellegrini, L. (2009). An empirical roadmap for intranet evolution. International Journal of Information Management, 29(4), 295-308.

Mphidi, H., \& Snyman, R. (2004). The utilisation of an intranet as a knowledge management tool in academic libraries. Electronic Library, 22(5), 393-400.

Robbins, S., Engel, D., \& Bierman, J. (2006). Using the library intranet to manage web content. Library Hi Tech, 24(2), 261-272.

Sult, L., \& Evangeliste, M. (2009). We are all librarians: Training in the ever evolving information commons. Reference Librarian, 50(3), 248-258. 